\title{
An episodic event of pollen transport of European beech
}

\author{
M. Piringer ${ }^{1}$, E. Polreich ${ }^{1}$, S. Schüler ${ }^{2}$, and K. Robitschek ${ }^{2}$ \\ ${ }^{1}$ Central Institute for Meteorology and Geodynamics, Vienna, Austria \\ ${ }^{2}$ Federal Research and Training Centre for Forests, Natural Hazards and Landscape, \\ Department of Genetics, Vienna, Austria
}

Received: 16 December 2009 - Revised: 5 February 2010 - Accepted: 12 February 2010 - Published: 18 February 2010

\begin{abstract}
The meteorological impacts on pollen emission and spread in a typical Central European forest of mixed deciduous and coniferous trees are investigated. Pollen samples as well as meteorological measurements have been conducted during the flowering period of spring flowering tree species in 2009. An episodic event of pollen transport to the study area is analyzed in detail with the aid of hourly backwards trajectories. The results indicate that the experimental set-up was well designed for a thorough meteorological analysis of the pollen counts.
\end{abstract}

\section{Introduction}

The scientific project "ROSALIA" investigated the meteorological impact on pollen emission and spread in a typical Central European forest of mixed deciduous and coniferous trees. For this purpose, simultaneous pollen counts and meteorological measurements at three platforms of a $36 \mathrm{~m}$ high meteorological tower have been carried out in April and May 2009. Several tree species have been taken into account. With the aid of $48 \mathrm{~h}$ backward trajectories calculated hourly with the trajectory model FLEXTRA (Stohl, 1998) based on data from the limited area model ALADIN run operationally with a horizontal resolution of $4.9 \mathrm{~km}$ at ZAMG, the area of the origin of pollen transported to the study site is analyzed.

\section{Experimental set-up}

The study area is the "Lehrforst Rosalia" of BOKU University approx. $60 \mathrm{~km}$ south of the city of Vienna in undulating terrain (300-750 m altitude, Fig. 1). Pollen counts are conducted on three levels of a meteorological tower situated in a narrow tree-covered valley at $410 \mathrm{~m}$ height (left triangle in Fig. 1) for the flowering period of spring flowering tree species in 2009. The tower is located directly within the crowns of a mixed stand of European beech, Sessile oak, Norway spruce, Silver fir and Common ash. The first upper sampling unit $36 \mathrm{~m}$ above ground measures the pollen concentration above the canopy, the second sampling unit is installed in the crown sphere of the stand $22 \mathrm{~m}$ above ground and the third sampling unit measures the pollen concentration $5 \mathrm{~m}$ above the forest ground. In order to sample pollen from all directions and to account for the potential turbulence within the canopy, a cylindrical pollen separator as suction device and the conventional Burkard pollen impactor with a $24 \mathrm{~h}$ drive as impactor and detection device are applied (Hirst, 1952).

Meteorological parameters, especially the threedimensional wind and turbulence indicators, have been measured with ultrasonic anemometers at the same heights as the pollen counts on the tower. The several levels of observation on the tower are necessary as meteorological parameters and turbulent fluxes cannot be assumed to be constant with height (Klemm et al., 2006; Froelich et al., 2006) in this complex environment. Sonic anemometers deduce the magnitude of the along-path velocity component from the travel time of acoustic waves between transducers separated about 10 to $20 \mathrm{~cm}$. In addition to the threedimensional wind vector, the sound velocity is derived, from which the so called "sonic temperature" is calculated. The measurement of sonic temperature fluctuations is necessary to calculate the sensible heat flux. Other quantities which are derived from sonic measurements are the means, standard deviations, and co-variances of the wind components and the momentum flux, the Monin-Obukhov stability parameter, and the friction velocity. 


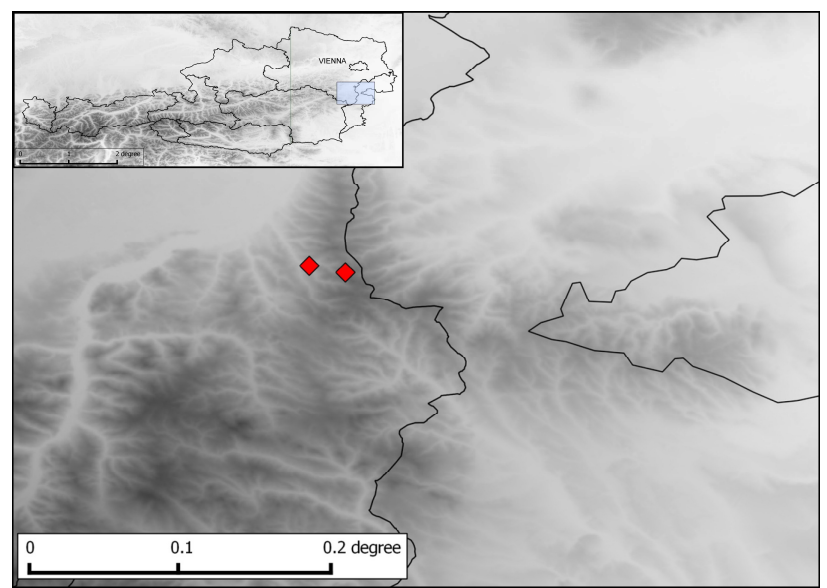

Figure 1. Location of the meteorological towers (red triangles) in the Rosalia mountains (Lehrforst Rosalia) and schematic location of the Lehrforst in Austria. Scale is in degrees $\left(0.2^{\circ}\right.$ is approx. $15.5 \mathrm{~km})$.

\section{Results and discussion}

Within a radius of approx. $50 \mathrm{~m}$ around the tower, all 487 trees have been identified, marked, measured and mapped. Every 2 to 4 days, the trees were visually surveyed for the state of flowering and flushing. This started on 7 April 2009, and ended on 15 May 2009. From this survey, the leaf-off period was determined to end on 20 April, with the leaf-on period starting on 21 April. In the following, a pollen event of European beech on 23 April is analyzed in detail. European beech did not blossom at this date in the vicinity of the observation site, so the occurrence of pollen is attributed to atmospheric transport only.

The pollen counts during the night to 23 April (Fig. 2a) show enhanced levels of pollen of European beech at all three measurement levels between approx. 03:00 and 05:00 local time (UTC $+2 \mathrm{~h})$. Pollen is however not transported in a homogeneous cloud, but rather in single plumes, resulting in sometimes quite large differences in pollen levels with time and height. The night-time occurrence of this peak is another hint for pollen transport to the site. The measured peak of pollen coincides with a period of westerly - up-valley winds at the top and middle levels of the tower. There is considerable wind shear within the canopy, also seen from the time course of wind speed (Fig. 2b) which is very low during this night but shows enhanced values of $1 \mathrm{~ms}^{-1}$ at the top of the canopy during this episode. So clearly there is up-valley transport from the flatlands north-west of the site through the narrow valley, impinging on the slope where the tower is situated.

The two other meteorological parameters displayed in Fig. 2c give an indication of atmospheric stability during this episode. $\sigma_{w}$ is a measure of vertical exchange. It is low within the canopy, as expected, but shows high values on top

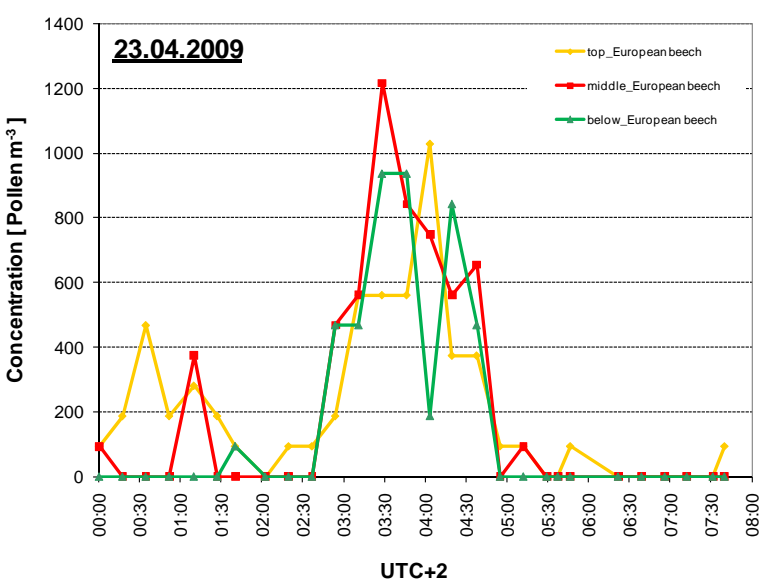

Figure 2a. Pollen concentrations (Pollen $\mathrm{m}^{-3}$ ) of European beech on 23 April 2009, at the three levels of the tower.

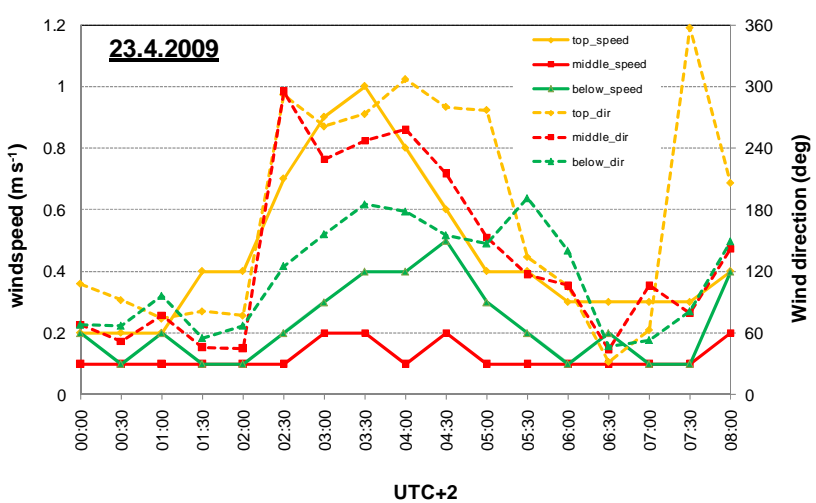

Figure 2b. Time series of wind speed ( $\mathrm{m} \mathrm{s}^{-1}$, solid lines) and wind direction (degrees, dashed lines) on 23 April 2009, at the three levels of the tower.

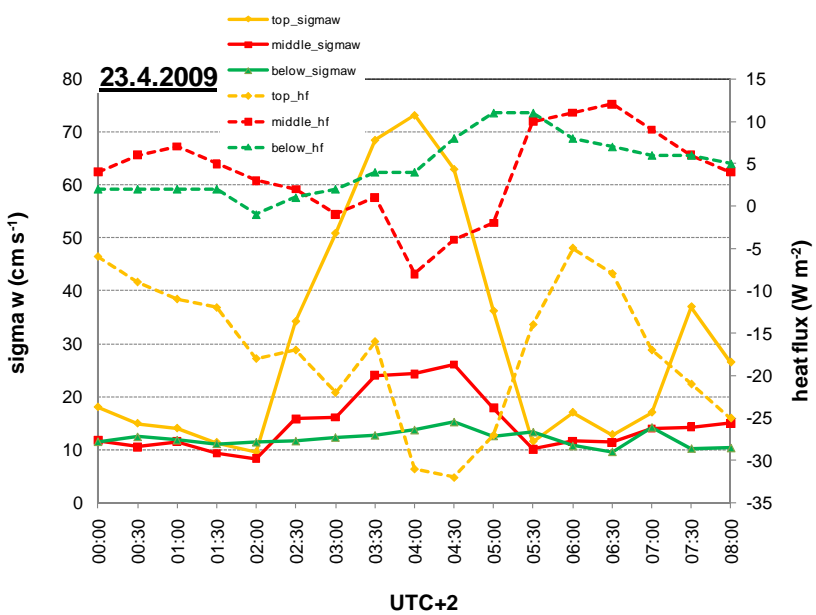

Figure 2c. Time series of $\sigma_{w}\left(\mathrm{~cm} \mathrm{~s}^{-1}\right.$, solid lines) and sensible heat flux ( $\mathrm{W} \mathrm{m}^{-2}$, dashed lines) on 23 April 2009, at the three levels of the tower. 


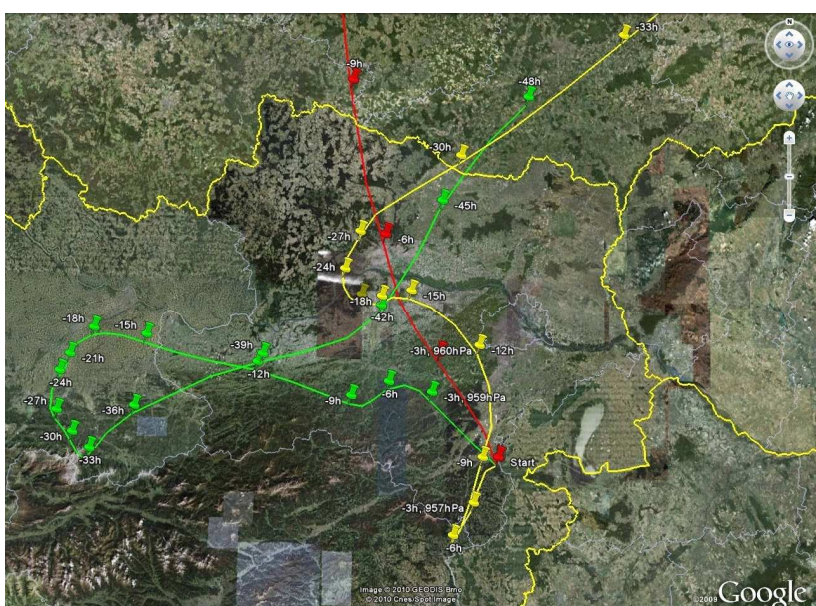

Figure 3. Ground-level $48 \mathrm{~h}$ backward trajectories arriving on 23 April 2009, at 01:00 (yellow line), 04:00 (green line) and 07:00 (red line) local time (UTC $+2 \mathrm{~h})$.

of the canopy during the episode with high pollen counts, affirming the assumption that pollen is transported to the area and originates from outside the canopy. The sensible heat flux is negative on top of the canopy, indicating night-time heat loss, as expected. This increases during the period of enhanced wind speed and $\sigma_{w}$. The loss of heat decreases within the canopy and partly reverses at the lowest level. Apparently the dense canopy stores heat produced during the day in a similar way as the urban canopy (Piringer et al., 2002) and releases it during the night, resulting in a positive (i.e. directed to the ground) sensible heat flux.

Finally, also the $48 \mathrm{~h}$ backwards ground-level trajectories displayed in Fig. 3 for different arrival times indicate the area of origin of the observed pollen. According to the observed temporal development of pollen concentration at the site some pollen before 3:00 local time, pollen peak between 03:00 and 05:00 h, almost no pollen afterwards - one characteristic trajectory for each time interval is displayed. The trajectory arriving at 01:00 local time at the tower (yellow line in Fig. 3) comes from the north, crossing the flatlands along the river Danube west of Vienna and the Vienna basin, lowlevel areas where the beech could have already blossomed. The 04:00 h trajectory (green line in Fig. 3) is the slowest, with a long residence time over the North-Alpine foreland where pollen must have been set free the day before; similar trajectories are obtained for 03:00 and 05:00 local time (not shown), well explaining the pollen peaks measured at the tower during this period. The 07:00 local time trajectory (red line) is subject to increasing wind speeds and comes straight almost from north where apparently no blossoming of European beech had yet occurred. The 06:00 and 08:00 $\mathrm{h}$ trajectories (not displayed) show similar paths. The pollen transport episode can thus well be explained by both the meteorological measurements as well as the trajectory analysis.

\section{Conclusions}

The meteorological impacts on pollen emission and spread in a typical Central European forest of mixed deciduous and coniferous trees are investigated by simultaneous pollen counts and meteorological measurements at three platforms of a $36 \mathrm{~m}$ high meteorological tower in April and May 2009. With the aid of $48 \mathrm{~h}$ backward trajectories calculated with the trajectory model FLEXTRA (Stohl, 1998) based on ALADIN data, the area of the origin of pollen transported to the study site is analyzed.

A pollen event of European beech on 23 April is analyzed in detail. Both the instrumentation set up on the tower as well as the trajectory model can well explain origin and transport of pollen to the study area in this particular night.

Acknowledgements. The authors thank their colleague Kathrin Baumann-Stanzer for continuing support and discussion and the two anonymous referees as well as the editor for evaluating this paper.

This research was enabled by the Austrian Science Fund under contract P20620-B16.

Edited by: A. Baklanov

Reviewed by: two anonymous referees

\section{References}

Froelich, N. J., Schmid, H. P., Grimmond, C. S. B., Su, H.-B., and Oliphant, A. J.: Flow divergence and density flows above and below a deciduous forest. Part 1: Non-zero mean vertical wind above canopy, Agr. Forest Meteorol., 133, 140-152, 2005.

Froelich, N. J. and Schmid, H. P.: Flow divergence and density flows above and below a deciduous forest. Part 2:Below-canopy thermographic flows, Agr. Forest Meteorol., 138, 29-43, 2006.

Hirst, J. M.: An automatic volumetric spore trap, Ann. Appl. Biol., 39, 257-265, 1952.

Klemm, O., Held, A., Forkel, R., Gasche, R., Kanter, H.-J., Rappenglück, B., Steinbrecher, R., Müller, K., Plewka, A., Cojocariu, C., Kreuzwieser, J., Valverde-Canossa, J., Schuster, G., Moortgat, G. K., Graus, M., and Hansel, A.: Experiments on forest/atmosphere exchange: Climatology and fluxes during two summer campaigns in NE Bavaria, Atmos. Environ., 40, Suppl. 1, 3-20, 2006.

Piringer, M., Grimmond, C. S. B., Joffre, S. M., Mestayer, P., Middleton, D. R., Rotach, M. W., Baklanov, A., De Ridder, K., Ferreira, J., Guilloteau, E., Karppinen, A., Martilli, A., Masson, V., and Tombrou, M.: Investigating the Surface Energy Balance in Urban Areas - Recent Advances and Future Needs, Water Air Soil Poll., 2, 1-16, 2002.

Stohl, A.: Computation, accuracy and applications of trajectories a review and bibliography, Atmos. Environ., 32, 947-966, 1998. 